\title{
MELHORES PRÁTICAS NA PERSPECTIVADE ENFERMEIROS DA REDE DE ATENÇÃO À SAÚDE
}

\author{
Mônica Ludwig Weber ${ }^{1}$ \\ Carine Vendruscolo ${ }^{1}$ \\ Edlamar Kátia Adamy ${ }^{1}$ \\ Clarissa Bohrer da Silva ${ }^{1}$
}

\begin{abstract}
http://orcid.org/0000-0001-6593-446X
http://orcid.org/0000-0002-5163-4789

http://orcid.org/0000-0002-8490-0334

http://orcid.org/0000-0002-1254-019X
\end{abstract}

Objetivo: compreender e estimular o desenvolvimento de melhores práticas entre enfermeiros de uma Rede de Atenção à Saúde. Metodologia: pesquisa-ação, alicerçada no referencial metodológico de Paulo Freire. Realizaram-se três Círculos de Cultura, com 10 enfermeiros atuantes no Oeste de Santa Catarina, entre os meses de junho a agosto de 2018. As informações foram analisadas à luz dos atributos da Atenção Primária à Saúde. Resultados: o ideário das melhores práticas converge com estratégias como a interlocução, integração e apoio entre enfermeiros e demais profissionais da Rede, constituindo a base para uma $A t^{12}$ enção Primária resolutiva. Os desafios para a sua realização perpassam a mudança do modelo de atenção, refletindo, sobretudo, na efetivação dos atributos essenciais na Atenção Primária. Conclusões: o estudo provocou a reflexão e, em certa medida, a reconstrução da práxis dos enfermeiros, que se percebem como protagonistas, no âmbito do sistema de saúde.

Descritores: Serviços de Saúde, Enfermagem, Educação Continuada, Conhecimentos, Atitudes e Prática em Saúde.

\section{BEST PRACTICES FOR NURSES IN THE HEALTH CARE NETWORK}

Objective: to understand and encourage the development of best practices among nurses in a Health Care Network. Methodology: action research, based on Paulo Freire's methodological framework. Three Culture Circles were held with 10 nurses working in the West of Santa Catarina, between the months of June to August 2018. The information was analyzed in the light of the attributes of Primary Health Care. Results: the ideal of best practices converges with strategies such as interlocution, integration and support between nurses and other professionals of the Network, constituting the basis for resolving Primary Care. The challenges for its realization permeate the change in the model of care, reflecting, above all, in the realization of the essential attributes in Primary Care. Conclusions: the study provoked reflection and, to a certain extent, the reconstruction of the praxis of nurses, who perceive themselves as protagonists, within the scope of the health system.

Descriptors: Health Services, Nursing, Continuing Education, Health Knowledge, Attitudes and Practice.

\section{MEJORES PRÁCTICAS PARA ENFERMERAS EN LA RED DE ATENCIÓN MÉDICA}

Objetivo: comprender y fomentar el desarrollo de mejores prácticas entre enfermeras en una Red de Atención Médica Metodología: investigación de acción, basada en el marco metodológico de Paulo Freire. Se realizaron tres Círculos de Cultura, con 10 enfermeras que trabajan en el oeste de Santa Catarina, entre los meses de junio a agosto de 2018. La información se analizó a la luz de los atributos de La Atención Primaria de Salud. Resultados: el ideal de las mejores prácticas converge com estrategias como la interlocución, integración y apoyo entre enfermeras y otros profesionales de la Red, que constituy en la base para resolver la Atención Primaria. Los desafíos para su realización impregnan el cambio en el modelo de atención, reflejando, sobre todo, en la realización de los atributos esenciales en Atención Primaria. Conclusiones: el estudio provoco la reflexión y, en cierta medida, la reconstrucción de la praxis de las enfermeras, que se perciben a si mismas como protagonistas, dentro del alcance del sistema de salud.

Descriptores: Servicios de Salud, Enfermería, Educación Continua, Conocimientos de Salud, Actitudes y Práctica.

IUniversidade do Estado de Santa Catarina (UDESC), Florianópolis, SC, Brasil.

Autor Correspondente: Mônica Ludwig Weber Email: monyludwig@hotmail.com Recebido: 14/2/20 Aceito: 20/7/20 


\section{INTRODUÇÃO}

Os atributos essenciais da Atenção Primária à Saúde (APS): o acesso, a longitudinalidade, a integralidade e a coordenação do cuidado ${ }^{1}$ conferem à esse nivel de atenção a responsabilidade de coordenar os cuidados básicos à população, o que corresponde à resolução de $80 \%$ dos problemas de saúde e, em situações mais complexas, direcionar o usuário para outros pontos da Rede de Atenção à Saúde (RAS) $)^{2.3}$. No Brasil, o Sistema Único de Saúde (SUS) promove ampla difusão da Estratégia Saúde da Família (ESF), cuja ideia de equipe multidisciplinar passou a ser aspecto estruturante do trabatho na APS, evidenciando o conceito da interprofissionalida$\mathrm{de}^{4}$. O trabalho colaborativo das equipes corrobora para o sucesso do arranjo organizativo horizontal da RAS, com diferentes pontos de atenção e densidades tecnológicas que buscam garantir a integralidade do cuidado ${ }^{3.5}$.

O enfermeiro se destaca neste cenário por sua formação generalista, que the confere habilidade para transitar entre as disciplinas da saúde e estabelecer vínculos com os diversos profissionais que compõe a equipe de saúde. No entanto, sua atuação, considerando os atributos da APS ainda representa um desafio. Nessa direção emergem as "melhores práticas", termo que se refere às ações pautadas pela experiência profissional, considerando as necessidades do usuário, e pela melhor evidência disponivel, com o objetivo de produzir resultados satisfatórios para os usuários, família e comunida$\mathrm{de}^{6,7}$. O enfermeiro é considerado o elo articulador entre os profissionais da equipe, neste sentido, precisa potencializar. constantemente, ferramentas e estratégias como o diálogo, a empatia e a interlocução entre diferentes saberes, além do exercício da criatividade, da experiência e de habilidades aplicadas à contextos específicos, com a racionalização de recursos para o alcance de resultados 8 .

Diante dessas exposições, questiona-se como tem se desenvolvido as práticas dos enfermeiros para qualificar o cuidado, considerando os atributos da APS? O objetivo deste estudo foi compreender e estimular o desenvolvimento de melhores práticas entre enfermeiros de uma RAS.

\section{MÉTODO}

\section{Tipo de estudo}

Estudo qualitativo do tipo pesquisa-ação desenvolvido com base no Método de Paulo Freire. Essa modalidade de pesquisa tem como campo de estudo o contexto real do participante, articulado à ação para a resolução de um problema coletivo, de modo cooperativo. Adotou-se o Itinerário Freireano, mediante as fases: 1) investigação temática, 2) codificação e descodificação e 3) desvelamento crítico?.

\section{Local do estudo}

A pesquisa foi realizada em uma RAS constituída por três municípios, situados no Oeste de Santa Catarina, com população aproximada de 18 mil habitantes, e que conta com serviços de atenção primária, secundária e terciária.

\section{Participantes da pesquisa}

Os participantes foram 10 enfermeiros, assim distribuídos: cinco da APS, dois da atenção secundária e três da atenção terciária. O critério de inclusão foi atuar no serviço por, no mínimo, três meses e foram excluídos enfermeiros em licença ou afastados por qualquer motivo.

\section{Coleta de dados}

Os três Círculos de Cultura (CC), utilizados como forma de produção e registro das informações ocorreram entre os meses de junho a agosto de 2018, com intervalo de aproximadamente 21 dias entre os encontros. A dinamicidade e flexibilidade dos CC permite um número irregular de participantes, desde que se oportunize a aproximação entre pesquisadores e participantes, e as situações limites se tornem uma possibilidade de interesse coletivo". Com duração de cerca de duas horas, os CC ocorreram em um dos serviços da RAS, foram previamente agendados e gravados, mediante livre e esclarecido consentimento dos participantes.

No primeiro CC, fase da investigação temática, o tema e objetivos da pesquisa foram apresentados aos nove enfermeiros (cinco da APS, um da atenção secundária e três da atenção terciária). Questões disparadoras nortearam a discussão sobre a prática profissional do enfermeiro na RAS. Ao término, a mediadora organizou um painel com os principais temas geradores (TG) - palavras que são extraídos do universo vocabular do sujeito, de acordo com seu cotidiano de vida?

No segundo CC, com oito enfermeiros (quatro da APS, um da atenção secundária e três da atenção terciária), resgatou-se o painel; os TG foram agrupados e/ou suprimidos, de acordo com a significância atribuída por eles. Avançou-se para a fase de codificação e descodificação. Os enfermeiros foram convidados a refletir sobre melhores práticas, nas diferentes dimensões de atuação: gestão, assistência, ensino e pesquisa, considerando os atributos da APS. Para isso, reuniram-se em dois grupos, sendo que um identificou práticas na gestão-assistência e o outro no ensino-pesquisa. Posteriormente, foram invertidos os participantes de cada grupo para que todos contribuíssem na construção. Novo painel foi apresentado e discutido no grande grupo.

No terceiro encontro, com a presença de seis enfermeiros (três da APS e três da atenção terciária), à medida que os TG dos encontros anteriores foram analisados, uma situação que antes era considerada empírica recebeu novo olhar, possibilitando o desvelamento crítico. Os participantes refletiram sobre a realidade e seu papel frente às situações limite, proje- 
tando possíveis movimentos de mudança.

\section{Procedimento de análise dos dados}

O procedimento de análise temática ocorreu concomitantemente à sua produção, à luz dos atributos da APS. Em todas as etapas da investigação, os pesquisadores realizaram a transcrição do material gravado em áudio e organizaram os registros para sistematizar as informações (redução temática) e apresentá-las de modo organizado aos participantes, validando-as'. Dentre os TG, este artigo explora as "melhores práticas em enfermagem".

\section{Procedimentos éticos}

A pesquisa foi desenvolvida conforme as diretrizes da Resolução no 466/12 do Conselho Nacional de Saúde para pesquisas envolvendo seres humanos, parecer de aprovação no Comitê de Ética em Pesquisa local sob número 2.380.748 de novembro de 2017. Os participantes foram designados com nomes de pedras preciosas.

\section{RESULTADOS}

Quando questionados sobre as melhores práticas de sua atuação na RAS, os participantes remeteram ao protagonismo da enfermagem na constituição do cuidado individualizado/integral (atributo integralidade) e do acesso ao serviço (atributo acesso) e vínculo longitudinal de cuidado com o usuário (atributo longitudinalidade), na direção da prevenção de agravos e da promoção da saúde, considerando o modelo de atenção vigente:

[...] gente é protagonista do cuidado [...]o cuidado é individualizado[...] a gente presta a assistência a cada um na busca do bem-estar. (Cristal)

[...]a gente vem trabalhando bastante a prevenção [...] só conversar, trocar uma ideia, às vezes era só isso que a pessoa queria, não precisa nem consultar, nem iniciar com remédio, apenas dar uma atenção que a pessoa já sai diferente, melhor. (Ágata)

Nesse sentido, as melhores práticas emergem na fala dos enfermeiros como a prática clínica pautada em evidências, seja na tomada de decisão para realização de punção venosa ou de curativo, a qual envolve a experiência profissional e a interlocução entre os profissionais. Além disso, o acompanhamento longitudinal do paciente, a exemplo da puericultura, também aparece como uma melhor prática.

Eu vejo um exemplo [de melhor prática] a questão da punção venosa, a escolha do dispositivo está diretamente ligada ao estado geral do paciente, ao que você deseja infundir, sempre tentando considerar o que é menos dispendioso em matéria de custos, a vontade do paciente e nossa experiência. (Cristal)

[...] a gente tinha o caso de uma paciente que a cobertura do curativo que estávamos usando não era efetiva, ai tanto eu quanto o médico e a técnica fomos pesquisar para ver qual seria que a gente poderia utilizar na paciente. (Turmalina)

Na Atenção Básica a gente vê o todo, ele[usuário] inserido na sociedade, na familia. [...]Se tu vais fazer um acompanhamento com uma criança, na puericultura, essa continuidade demonstra uma melhor prática. (Jade)

Por outro lado, os enfermeiros referiram percepções críticas sobre possiveis obstáculos à realização de melhores práticas, especialmente na APS, os quais perpassam aspectos relativos à gestão dos serviços e à formação profissional para uma atuação direcionada ao modelo de atenção desejado, ou seja, centrado no paciente e pautado na efetivação dos atributos essenciais na RAS. Os depoimentos também expressam uma percepção equivocada dos participantes sobre o modelo proposto na ESF:

[...]quando implantaram esses PSF [Programa Saúde da Família] que era para fazer a promoção e educação em saúde, no que virou? Em assistencialismo, saúde curativa! (Ametista)

Têm várias coisas que a gente faz, buscando sempre o melhor. Mas[...] temos esses empecilhos, de gestão e tudo mais [refere-se à gestão autoritária, má distribuição e escassez de recursos materiais e humanos], o que atrapalha na hora de implementar ações educativas ou de prevenção [...]. Ele [usuário] vai para algum especialista, para outro médico e volta de novo [para a APS] [...] a gente não consegue fazer esse acompanhamento, pois não se tem registro ou retorno da assistência oferecida[...]. (Jade)

Eu vejo o posto de saúde como uma rodoviária: o paciente não fica! A gente acompanha o paciente mais efetivamente no hospital, porque ele fica alguns dias. (Ametista)

Os participantes expressaram a necessidade de atualização e de qualificação profissional como uma forma de realizar melhores práticas, ou seja, práticas mais seguras e pautadas em evidências. Reconhecem a Enfermagem como uma categoria profissional em que são exigidos conhecimentos, habilidades, atitudes adequadas e atualizadas. Dessa forma, sina- 
lizam a necessidade de movimentos de aproximação com o ensino [Universidades] para atualização:

[...] no hospital, quem está 24 horas, feriados e finais de semana é o enfermeiro. Farmacêutico não vem, nutricionista não vem, psicólogos nós nem temos, médico é sobreaviso[...]a primeira conduta sempre é o enfermeiro. Se um paciente faz PCR [Parada Cardiorrespiratória] até que eu chame o médico eu já perdi o paciente, então eu vou ter que fazer, logo, preciso estar qualificada para isso. (Cristal).

Essa troca para a gente estar se atualizando, porque fora das universidades as coisas vão dificultando se a gente não se atualizar, precisa dessa troca. (Ametista)

Os participantes apontam a importância da melhoria contínua da qualidade dos serviços de saúde, a qual depende de profissionais comprometidos. Referem que o conhecimento científico, a experiência profissional e as ações colaborativas entre os diferentes profissionais e pontos da RAS, caracterizam-se como elementos constituintes para o desenvolvimento das melhores práticas.

É quase impossivel algum profissional não fazer o melhor. Eu penso que é o caminho sim, melhorar o serviço, acho que a experiência é muito importante [...] (Ametista)

Quanto melhor o teu conhecimento, melhor é a tua prática. Essa colaboração entre nós enfermeiros e a equipe eu estou achando maravilhoso, de ter contato com as colegas da Atenção Básica e CAPS [Centro de Apoio Psicossocial]. Quando você está no momento do trabalho, você está sobrecarregado, você fica no automático e não reflete muita coisa. Tu até sabes o ponto que estás com dificuldade, tanto com o paciente ou com o profissional, mas não pensa: vamos buscar um apoio, uma qualificação, uma melhoria. (Ônix)

Ao encerrar o desvelamento do universo temático, houve expressão dos participantes em relação aos CC como espaço para a construção de novas ideias e de transformação das práticas visando uma atuação operacionalizada pelos atributos essenciais e pautada na qualidade da atenção.

[...] esses momentos nos fazem refletir sobre o que fazemos e onde queremos chegar. Muito válido para conhecer a realidade da atenção básica, que a gente que está no outro ponto as vezes julga, não entende, não sabe o que acontece. E isso reflete na assistência mais continua, integral, pois você sabe que pode contar com o enfermeiro do outro serviço. (Cristal)

A partir dos diálogos e trocas de experiências, o grupo se propôs a fomentar momentos de interlocução, visando articular os pontos de produção de saúde da RAS. Decidiu-se, então, promover a integração entre enfermeiros da RAS, iniciando com a realização de grupos educativos de gestantes, sendo uma demanda visualizada com necessidade de melhoria de atuação pelos profissionais dessa RAS. Foram realizados dois grupos, em dois municípios, com a presença de gestantes, Agentes Comunitários de Saúde (ACS), enfermeiras da atenção terciária e APS e a médica obstetra.

\section{DISCUSSÃO}

O estudo evidencia a compreensão das melhores práticas entre enfermeiros que atuam na RAS. Na medida em que os participantes ressaltaram o protagonismo da Enfermagem na constituição do cuidado pautado nos atributos essenciais na RAS, se revelam as dimensões de atuação do processo de trabalho da profissão: o cuidado, a educação/pesquisa e o gerenciamento ${ }^{10}$. O cuidado tem como objeto de intervenção as pessoas com necessidades relacionadas ao processo saúde-doença, o que demanda um campo de conhecimentos da saúde coletiva e da prática clínica/assistencial. A pesquisa implica nas evidências que permeiam o processo de cuidar, a educação popular e também a educação permanente. O gerenciamento articula as atividades de organização do trabatho, o que pressupõe liderança e participação"1.

Nesse sentido, as melhores práticas emergiram na fala dos enfermeiros como a prática clínica pautada em evidências que envolve o conhecimento científico e a experiência profissional. Soma-se a isso, a colaboração interprofissional a qual corrobora para a reflexão crítica. Ao atuarem em colaboração, profissionais de diferentes áreas demonstram melhor desempenho, com impacto na integralidade ${ }^{12}$.

Os resultados indicam que os enfermeiros atribuem a possibilidade de vínculo com o usuário à garantia da continuidade e integralidade do cuidado. A integralidade remete à necessidade de mudança, especialmente na abordagem interprofissional, que implica diálogo e colaboração entre as áreas com objetivo de perceber as reais necessidades da população 4 .

Além disso, evidenciou-se a importância da melhoria contínua da qualidade dos serviços de saúde, a qual depende de profissionais comprometidos. Estudo destacou, dentre os fatores associados ao melhor desempenho da APS: a formação dos profissionais em saúde da família, a disponibilidade 
do médico na equipe 30 horas semanais e o número de equipes por UBS, suscitando a necessidade de ampliá-las e/ou reestruturá-las, a fim de acomodar mais equipes e possibilitar maior integração ${ }^{13}$. Estas necessidades convergem com a realidade referida. O fato de ser uma RAS com serviços de baixa, média e alta complexidade poderia ser positivo ao se estudar estratégias de articulação e estabelecimentos de fluxos para o desenvolvimento de melhores e integradas práticas.

Entende-se que algumas fragilidades, como a escassez de pessoal, a gestão ineficiente e as condutas clínicas dos profissionais sobrecarregados, corroboram para a falta de qualificação e desmotivação nos serviços. De maneira convergente, pesquisa evidencia que a sobrecarga e as más condições de trabalho contribuem para o abandono de algumas funções dos profissionais ${ }^{14}$

Os resultados revelam a falta de interlocução entre enfermeiros e demais profissionais, bem como entre os pontos da rede, evidenciando a inexistência de Linhas de Cuidado formalmente instituídas ${ }^{15}$. Estas representariam fluxos assistenciais garantidos aos usuários, incluindo os serviços que não estão necessariamente, inseridos no Sistema, como entidades comunitárias, mas que participam da Rede $e^{15,16}$

No cenário de estudo, não há registro formalizado sobre a assistência prestada nos diferentes pontos da RAS, com vistas à coordenação do cuidado pela APS. No Canadá, Espanha e Portugal, alguns serviços operam apoiados no conceito de "Enfermeiro de Ligação"17, o qual corresponde ao profissional que realiza a articulação na rede (contrarreferência do usuário entre os pontos de atenção, na lógica da clínica ampliada). Embora essa discussão, no Brasil, não tenha encontrado significância, tal atividade pode evoluir para outras expressões já ascendidas, como a Enfermagem de Prática Avançada, e colaborar com a aproximação entre os serviços e o fluxo de informações ${ }^{17,18}$

Cabe destacar que os participantes também referiram percepções críticas sobre possiveis obstáculos à realização de melhores práticas, como a dificuldade de mudança de um modelo biomédico e curativista para um modelo centrado no paciente e integral. Destaca-se que a mudança de modelo perpassa também, a compreensão da equipe sobre a lógica da APS, donde os dados demonstram fragilidade. Além disso, é preciso levar em conta o atributo atenção ao primeiro contato (acesso), que traz a ideia de que a organização da RAS a partir da APS facilita a porta de entrada para cada novo problema ou episódio pelo qual as pessoas buscam cuidado, sendo, a partir desse atendimento, referenciado aos demais pontos da $\operatorname{Rede}^{2,19}$. Nessa direção, sabe-se da relevância de profissionais qualificados na APS para exercer a "função filtro" (tomada de decisão sobre quando acessar cuidados especializados). Essa medida pode evitar a burocratização excessiva e o aumento do número de encaminhamentos aos serviços especializados ${ }^{16}$.

Nesta perspectiva, os enfermeiros compreendem que para realizar melhores práticas necessitam de atualização e de qualificação profissional sinalizando a importância de movimentos de aproximação com as instituições de ensino. Manter os profissionais de enfermagem atualizados corrobora para a realização de uma assistência mais segura de modo a evitar ações iatrogênicas e desnecessárias ${ }^{20,21}$

Os resultados desse estudo provocaram a reflexão e, em certa medida, a reestruturação da práxis, culminando com ações efetivas naquele cenário. A oportunidade de encontro, promovida pelos CC, ocasionou um processo efetivo de EPS. Apoiada no ensino problematizador, que segue os pressupostos pedagógicos formulados pela Organização Panamericana de Saúde e Organização Mundial da Saúde (OPAS/OMS) desde a década de 1980, também expressos nas obras do educador brasileiro Paulo Freire, a educação permanente aponta para a ação libertadora/emancipadora ${ }^{9,22}$. Essa abordagem propõe o protagonismo dos sujeitos, por meio da intervenção crítica na realidade, a partir da aprendizagem significativa, expressa pelo interesse nas suas experiências anteriores. Ao substituírem a postura de expectadores pela de protagonistas, nos diferentes pontos da RAS, os enfermeiros reconhecem sua autonomia e, nessa condição, assumem responsabilidades, comprometem-se, participam e desenvolvem o senso de pertencimento 22

\section{Limitações do estudo}

Como limitação do estudo, indica-se a dificuldade para reunir os profissionais para participarem dos encontros e a ampliação para outras RAS.

\section{Contribuição do estudo para a prática}

Este estudo possibilitou ampliar as reflexões sobre as melhores práticas, assim como permitiu o conhecimento e a aproximação dos enfermeiros com uma metodologia de pesquisa problematizadora, os Círculos de Cultura. Destaca-se a importância da educação permanente em saúde, fortalecendo a interlocução entre os profissionais e a Rede. Os resultados da pesquisa podem ser apresentados aos gestores dos serviços pois destacam a necessidade da elaboração e implementação de fluxos entres os diferentes pontos de atenção da Rede, o que favorecerá o trabalho interprofissional e a melhoria na assistência à saúde.

\section{CONSIDERAÇÕES FINAIS}

O ideário dos enfermeiros sobre as melhores práticas em enfermagem converge para a busca de evidências, experiência profissional e interlocução na RAS. Foi possível identificar lacunas na prática, atreladas, sobretudo, à falha na operacio- 
nalização dos atributos da APS como o acesso, a integralidade, a longitudinalidade e em especial a coordenação da atenção. Tais aspectos somados ao modelo de atenção ultrapassado limitam o desenvolvimento de melhores práticas.

É reveladora a perspectiva de que os enfermeiros se reconheceram como protagonistas do cuidado na RAS. O Itinerário Freireano provocou tal reflexão e, em certa medida, a reconstrução da práxis dos enfermeiros, pois os CC contribuiram para a criticidade e mobilização para a ação, como lócus de educação permanente. Sugere-se que sejam realizadas outras pesquisas sobre movimentos em direção às melhores práticas e o papel da enfermagem na articulação entre os pontos da RAS.

Contribuições dos Autores: MLW, CV e EKA: contribuiram com a concepção e/ou desenho do estudo. MLW, CV, EKA e CBS: Análise e interpretação dos dados, redação do artigo, revisão crítica e revisão final.

\section{REFERÊNCIAS}

1. Starfield B. Atenção primária: equilibrio entre necessidades de saúde, serviços e tecnologia. Brasília: UNESCO, 2002.

2. Portela GZ. Atenção Primária à Saúde: um ensaio sobre conceitos aplicados aos estudos nacionais. Physis (Rio J.). 2017 [acesso em 03 set 2019]; 27(2 ): 255-276. Disponivel em: http://dx.doi.org/10.1590/s0103-73312017000200005.

3. Mendes EV. A construção social da atenção primária à saúde. Brasília: Conselho Nacional dos Secretários de Saúde. 2015; vol 1: 1-193.

4. Silva MVS, Miranda GBN. Andrade MA. Sentidos atribuidos à integralidade: entre o que é preconizado e vivido na equipe multidisciplinar. Interface (Botucatu, Online).2017[acesso em 04 set 2019]; 21(62): 589-599. Disponivel em: http://dx.doi.org/10.1590/1807-57622016.0420.

5. Ceccim RB. Connections and boundaries of interprofessionality: form and formation. Interface (Botucatu, Online). 2018 [acesso em 04 set 2019]; 22: 1739-1749. Disponivel em: http://dx.doi.org/10.1590/1807-57622018.0477.

6. University Of Iowa (IOWA). College of Nursing. HCGNE - Best Practices for Healthcare Professionals. [Internet]. 2014 [acesso em 09 set 2019]. Disponivel em:http://www.nursing.uiowa.edu/hartford/best-practicesfor-healthcareprofessionals.

7. Organização Mundial da Saúde (OMS). Guia para a Documentação e Partilha das Melhores Práticas em Programas de Saúde. Brazzaville: OMS: 2008

8. Santos JLG, Lima MADS, Pestana AL, Colomé ICS, Erdmann AL. Strategies used by nurses to promote teamwork in an emergency room. Rev Gaúch Enferm. 2016 [acesso em 02 set 2019]; 37(1): e50178. Disponivel em: http://dx.doi.org/10.1590/1983-1447.2016.01.50178.

9. Heidemann ITSB, Dalmolin IS, Rumor PCF, Cypriano CC, Costa MFBNA, Durand MK. Reflexões sobre o Itinerário de Pesquisa de Paulo Freire: contribuições para a saúde. Texto \& Contexto Enferm. 2017 [acesso em 02 set 2019]; 26( 4 ): e0680017. Disponivel em: http://dx.doi. org/10.1590/0104-07072017000680017.

10. Forte ECN, Pires DEP, Scherer MDA, Soratto J. Muda o modelo assistencial, muda o trabalho da enfermeira na Atenção Básica? Tempus (Brasilia). 2018. [acesso em 02 set 2019]; 11(2):53-8. Disponivel em: http://www.tempusactas.unb.br/index.php/tempus/article/ view/2338/1777.

11. Nunes EFPA, Carvalho BG, Nicoletto SCS, Cordoni JL. Trabalho gerencial em Unidades Básicas de Saúde de municipios de pequeno porte no Paraná, Brasil. Interface (Botucatu, Online). 2016 [acesso em 02 set 2019]; 20(58): 573-584. Disponivel em: http://dx.doi. org/10.1590/1807-57622015.0065.

12. Lima JG, Giovanella L, Fausto MC, Bousquat A, Silva EV. Atributos essenciais da Atenção Primária à Saúde: resultados nacionais do PMAQ-AB. Saúde Debate. 2018 [acesso em 03set 2019]; 42: 52-66. Disponivel em: http://dx.doi.org/10.1590/0103-11042018s104.

13. Turci MA, Lima-Costa MF, Macinko J. The influence of structural and organizational factors on the performance of primary health care in Belo Horizonte, Minas Gerais State, Brazil, according to nurses and managers. Cad. Saúde Pública (Online). 2015 [acesso em 03 set 2019 ]; 31 (9): 1941-1952. Disponivel em: http://dx.doi.org/10.1590/0102-311X00132114.

14. Bertoncini JH, Pires DEP, Scherer MDA. Condições de trabalho e renormalizações nas atividades das enfermeiras na saúde da familia. Trab Educ Saúde (Online). 2011 [acesso em 02 set 2019]; 9: 157-173. Disponivel em: http://dx.doi.org/10.1590/S1981-77462011000400008.

15. Franco CM, Franco TB. Linhas do cuidado integral: uma proposta de organização da rede de atenção. São Paulo: 2015. Disponivel em: http://www.saude.sp.gov.br/resources/humanizacao/homepage/acesso-rapido/formacao-tecnica-em-acolhimento-na-atencaobasica/passo_a_passo_linha_de_cuidado.pdf.

16. Souza TP, Carvalho SR. Territorial support and multi-referential team: cartographies of the confluence between the method of support and the guidelines for harm reduction at a street-level among crack users and at the health network in the city of Campinas, SP. Brazil. Interface (Botucatu, Online).2014 [acesso em 27 ago 2019]; 18: 945-956. Disponivel em: http://dx.doi.org/10.1590/1807-57622013.0518.

17. Ribas EN, Bernardino E, Larocca LM, Poli Neto P. Aued GK, Silva CPC. Nurse liaison: a strategy for counter-referral. Rev Bras Enferm. 2018 [acesso em 02 set 2019]; 71( Suppl 1 ): 546-553. Disponivel em: http://dx.doi.org/10.1590/0034-7167-2017-0490.

18. Miranda Neto MV, Rewa T, Leonello VM, Oliveira MAC. Advanced practice nursing: a possibility for Primary Health Care?. Rev Bras Enferm. 2018 [acesso em 02 set 2019]; 71( Suppl 1): 716-721. Disponivel em: http://dx.doi.org/10.1590/0034-7167-2017-0672.

19. Montelo FM, Monturil LA, Moura EF, Barasuol AM, Dodero SR, Maciel ES et al. Avaliação dos atributos da Atenção Primária à Saúde: visão dos profissionais. Enferm em Foco [Internet]. 2020 [cited 2020 jun 27];10(6). Availablefrom: https://doi.org/10.21675/2357-707X.2019.v10. n6.2778.

20. Silva FML, Pimenta FJNA, Saraiva GBN, Barros MMA. Atualização profissional frente às práticas de enfermagem: um relato de experiência. Revista Eletrônica Acervo Saúde, 2019[acesso em 23jan 2020]; 32; ell86. Disponivel em:https://doi.org/10.25248/reas.el186.2019

21. Moll MF, Boff NN, Silva PS, Siqueira TV, Ventura CAA. O enfermeiro na Saúde da Familia e a promoção de saúde e prevenção de doenças. Enferm em Foco [Internet]. 2019 [acesso em 27 jun 2020]; 10(3). Disponivel em: https://doi.org/10.21675/2357-707X.2019.v10.n3.2001.

22. Vendruscolo C, Ferraz F, Prado ML, Kleba ME, Reibnitz KS. Teaching-service integration and its interface in the context of reorienting health education. Interface (Botucatu, Online).2016 [acesso em 04 set 2019]; 20 (59): 1015-25. Disponivel em: http://dx.doi.org/10.1590/180757622015.0768 . 